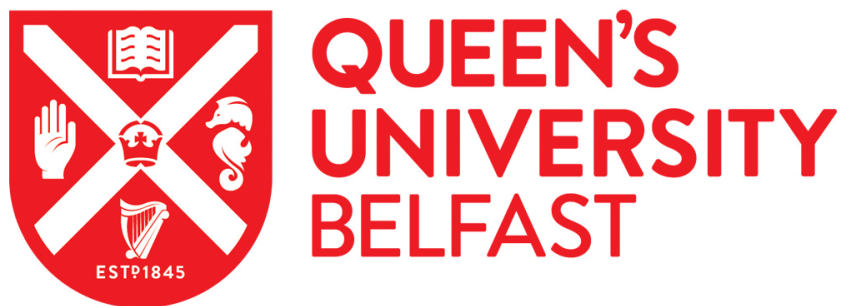

\section{Obesity, diabetes and zinc: A workshop promoting knowledge and collaboration between the UK and Israel, November 28-30, 2016 - Israel}

Jenkins, A., Lengyel, I., Rutter, G. A., Lowe, N., Shai, I., Tirosh, A., Petro, T., Khamaisi, M., Andrews, S., Zmora, N., Gross, A., Maret, W., Lewis, E. C., \& Moran, A. (2018). Obesity, diabetes and zinc: A workshop promoting knowledge and collaboration between the UK and Israel, November 28-30, 2016 - Israel. Journal of Trace Elements in Medicine and Biology, 49, 79-85. https://doi.org/10.1016/j.jtemb.2018.04.021

Published in:

Journal of Trace Elements in Medicine and Biology

\section{Document Version:}

Peer reviewed version

Queen's University Belfast - Research Portal:

Link to publication record in Queen's University Belfast Research Portal

\section{Publisher rights}

Copyright 2018 Elsevier $\mathrm{GmbH}$.

This manuscript is distributed under a Creative Commons Attribution-NonCommercial-NoDerivs License

(https://creativecommons.org/licenses/by-nc-nd/4.0/), which permits distribution and reproduction for non-commercial purposes, provided the author and source are cited.

\section{General rights}

Copyright for the publications made accessible via the Queen's University Belfast Research Portal is retained by the author(s) and / or other copyright owners and it is a condition of accessing these publications that users recognise and abide by the legal requirements associated with these rights.

\section{Take down policy}

The Research Portal is Queen's institutional repository that provides access to Queen's research output. Every effort has been made to ensure that content in the Research Portal does not infringe any person's rights, or applicable UK laws. If you discover content in the

Research Portal that you believe breaches copyright or violates any law, please contact openaccess@qub.ac.uk. 


\section{Obesity, Diabetes and Zinc: A Workshop Promoting Knowledge and Collaboration}

Between the UK and Israel, November 28-30, 2016 - Israel

Alicia Jenkins ${ }^{1,2, ~ *}$, Imre Lengyel ${ }^{1, *, \#}$, Guy A. Rutter ${ }^{3}$, Nicola Lowe $^{4}$, Iris Shai ${ }^{5}$, Amir Tirosh $^{6}$, Tunde Petro ${ }^{7}$, Mogher Khamaisi ${ }^{8}$, Simon Andrews ${ }^{9}$, Niv Zmora ${ }^{10}$, Atan Gross ${ }^{11}$, Wolfgang Maret $^{12}$, Eli C. Lewis ${ }^{13}$ and Arie Moran ${ }^{14,15}$

1. Centre for Experimental Medicine, Queens University, Belfast, UK;

2. NHMRC Clinical Trials Centre, University of Sydney, Australia;

${ }^{3 .}$ Faculty of Medicine, Department of Medicine, Imperial College, London, UK

4. School of Sport and Wellbeing, University of Central Lancashire Preston, UK

5. Department of Public Health School of Pharmacy, Ben Gurion University, Beer Sheva, Israel

6. The Institute of Endocrinology, Chaim Sheba Medical Center, Tel-Hashomer, Israel

7. Centre for Public Health, School of Medicine, Dentistry and Biomedical Science, Queen's University Belfast, UK

${ }^{8 .}$ Internal Medicine D and the Institute of Endocrinology, Diabetes and Metabolism, Rambam Medical Center and RB Rappaport Faculty of Medicine-Technion, Haifa, Israel.

9. School of Biological Sciences, University of Reading, Reading UK.

10. Department of Immunology Weizmann Institute of Science Rehovot, Israel

11. Department of Biological Regulation, Weizmann Institute of Science, Rehovot, Israel.

12. Department of Biochemistry \& Diabetes and Nutritional Sciences Division King's College London, UK.

13. Department of Clinical Biochemistry and Pharmacology, Faculty of Health Sciences, BenGurion University of the Negev, Beer Sheva, Israel. 
14. Dept. of Physiology and Cell Biology, Ben Gurion University of the Negev, Beer Sheva, Israel.

Keywords: Obesity, Diabetes, Zinc, inflammation

*Authors contributed equally.

\#Corresponding author:

Imre Lengyel, $\mathrm{PhD}$

The Wellcome-Wolfson Building, Centre for Experimental Medicine

School of Medicine, Dentistry and Biomedical Science

Queen's University Belfast, 97 Lisburn Road, Belfast, BT9 7BL

Telephone: +44 (0) 2890976027

Email: i.lengyel@qub.ac.uk 


\section{Introduction}

Sponsored by the Friends of Israel Educational Foundation (FIEF) and Ben-Gurion University of the Negev and supported by the EU COST action Zinc-Net (COST TD1304), a three-day collaborative UK-Israel workshop was organized by Drs Assaf Rudich, Imre Lengyel and Arie Moran. Participants from the UK and Israel met at the Desert Iris Hotel, Yeruham, Israel between the 28-30th of November 2016 for in-depth discussions, rather than a lecture series, to set the stage for future collaborative grants and projects on diabetes and zinc. Two days of formal scientific sessions with dynamic and wide-ranging discussions was followed by a day of touring and informal networking in the Negev area. This format was previously recognized by our sponsors as both effective and enjoyable and all participants agreed at the end of the meeting that the 3-days provided an excellent basis for future scientific collaboration. The discussions were centered on diabetes and obesity, already at pandemic levels, and zinc homeostasis which is related to the clinical issues and themes of the meeting. The free-flowing discussions were based on short presentations setting the scene for the six main topics: 'Diabetes and zinc transporters', 'Nutrition related factors', 'Biomarkers', 'Clinical epidemiology', 'the Microbiome and diabetes', and 'Related diseases'. The abstract style summary of the sessions is followed by the major discussion points raised by the Authors and other participants (UK: Patrik Rorsman, Oxford University; Alan Stewart, University of St Andrews and Israel: Assaf Rudich, Idit Liberty, Rahel Gol, Guy Las and Amos Katz, Ben-Gurion University; Sarah Zangen, Haddassa University). We hope that readers will find this discourse stimulating and some of the ideas might make their way into their research efforts.

\section{Obesity, Diabetes and Zinc}


Diabetes mellitus (DM), including Type 1 diabetes (T1DM), Type 2 diabetes (T2DM) and gestational diabetes, is a common devastating disease of dysglycaemia, affecting over 422 million people worldwide as of 2014 , with $\approx 75 \%$ of affected people living in disadvantaged regions where malnutrition may be common. As well as the acute effects of hyper- and hypoglycaemia DM is the cause for vascular and retino-, nephro- and/or neuro-pathy complications, a cardiomyopathy and is also associated with neurodegenerative disease and increased cancer incidence. Furthermore, diabetes can adversely impact pregnancy related outcomes for both mother and child. Zinc has long been recognised as key to insulin production, storage, secretion, and action. However, the connections between obesity, DM and its complications and zinc need significantly increased attention. Whilst heart failure is common in people with diabetes and there is increasing recognition of a specific diabetic cardiomyopathy, independent of ischemic heart disease and hypertension, due to a relative lack of specific expertise amongst attendees there was limited discussion in this important area.

\section{Zinc in diabetes: a review and perspective (Guy A. Rutter)}

Zinc levels are exceptionally high in pancreatic $\beta$ cells, $\sim 20 \mathrm{mmol} / \mathrm{L}$ in insulin-containing secretory granules. There are two $\mathrm{Zn}^{2+}$ ions at the core of each insulin hexamer and $\mathrm{Zn}^{2+}$ is essential for crystallization of insulin, as demonstrated by loss of normal electron dense granules in mice expressing a mutant insulin (HisB10Asp) defective in insulin binding. $\mathrm{Zn}^{2+}$ levels are reduced $\sim 75 \%$ in the diabetic pancreas, partly reflecting $\beta$ cell mass loss, and reduced insulin levels. $\mathrm{Zn}^{2+}$ is also critical to insulin signaling, affecting activity of phosphatases (e.g. PTP1B which dephosphorylates the insulin receptor), and activity of the adiponectin receptor, which 
regulates glucose utilization by skeletal muscle. Dietary $\mathrm{Zn}^{2+}$ supplementation studies to improve glucose homeostasis in rodents and in man have often been negative [1].

At least two genome-wide association studies (GWAS) for T2DM risk identified nonsynonymous variants in the SLC30A8 gene, encoding the secretory granule transporter ZnT8 [2]. ZnT8 expression is predominantly in mammalian pancreatic islet $\beta$ and $\alpha$ cells, making it a particularly interesting drug target. Whilst early studies suggested that the risk $(\mathrm{R})$ variant was less active [3], recent studies demonstrate that this $(\mathrm{R})$ variant is more active, which may explain why the rare, loss-of-function (LoF) variants protect against disease [4]. Nonetheless, more work is needed as mouse studies consistently show hyperglycaemia and/or an inhibition of insulin secretion after deletion of ZnT8 globally or in the $\beta$ cell. Indeed, it may be that the chief effect of $\mathrm{ZnT} 8$ deletion is to lower $\mathrm{Zn}^{2+}$ release from the $\beta$ cell which, in turn, enhances hepatic insulin clearance to impair peripheral insulin action $[5,6]$. Whether lowered $\mathrm{Zn}^{2+}$ levels close to the islet persists after entry into the portal vein and the systemic circulation is debated and difficult to test experimentally. Nonetheless, ratios of C-peptide to insulin are increased in risk allele carriers in man, consistent with this hypothesis. Interestingly, ZnT8 is also expressed in $\alpha$ cells [7], and in contrast to earlier reports our recent findings using mice inactivated selectively for ZnT8 or overexpressing the transporter in $\alpha$ cells demonstrate a negative correlation between ZnT8 expression and glucagon secretion, i.e. increased secretion as ZnT8 levels fall. These findings argue that lowered ZnT8 (by increasing glucagon) should raise glucose levels. Therefore, the mouse data imply positive actions for ZnT8 (increased insulin, lowered glucagon) and, in contrast to LoF variant data suggest that pharmacologic activation of ZnT8 might be clinically helpful [8]. The development and testing of small molecular activators and inhibitors in animals 
and man is desirable. Despite all the information on ZnT8 and the role for zinc in insulin crystals the impact of changing zinc levels in DM are yet to be discovered.

\section{Nutrition effects - I}

Malnutrition, zinc status and diabetes (Nicola Lowe)

Malnutrition encompasses both under-nutrition and adiposity. The "double burden" of malnutrition can cause both stunted growth, deficiencies in essential nutrients alongside obesity in populations and within families. The prevalence of overweight and obesity among women aged 20-49 years is up to $70 \%$ in the Americas and Caribbean, and $>40 \%$ in Europe [9]. Obese pregnant women are more likely to develop gestational diabetes and later in life T2DM [10]. A systematic review of six Prospective Cohort Studies examined the relationship between zinc status or intake and T2DM risk. Only one study reported a reduced T2DM risk with increasing dietary zinc, four reported no association and one an increased risk of T2DM. A recent systematic review and meta-analysis examined relationships between dietary zinc intake and status in people with vs. without DM, and found significantly lower zinc intakes in the T2DM group, which may be due to a lower calorie diet to treat their concurrent obesity. In addition, their serum zinc concentration was significantly lower than in healthy controls, consistent with altered zinc metabolism due to concurrent inflammation, and/or an increase in urinary zinc excretion, both of which occur in T2DM [11]. What about zinc supplementation and glycaemia? A metaanalysis revealed that zinc supplementation was associated with significantly lower fasting blood glucose levels and a trend to lower HbAlc levels. In summary, zinc status may be compromised in obesity and in T2DM, and changes in zinc homeostasis are likely present in DM. 
Interpretation of plasma zinc levels as a biomarker of zinc status is problematic due to the confounding by concurrent inflammation. Future studies should consider alternative biomarkers such as hair or nail zinc concentrations, or measures of DNA fragmentation.

The discussion explored the impact of the timing of zinc supplementation on the potential therapeutic impact on T2DM. There was extensive discussion on methods for the collection and storage of plasma for zinc determination [12] and what biomarkers could best reflect an individual's zinc status. The conclusion was that as yet there is no reliable circulating biomarker for clinical use.

\section{Nutrition effects - II}

Fat deposits and lifestyle changes in humans (Iris Shai)

It remains unclear whether specific lifestyle strategies can differentially mobilize fat /ectopic-fatdeposits. Iris Shai described an 18-month trial in an isolated workplace with monitored and provided lunch, where participants with abdominal obesity/dyslipidaemia were randomly assigned to a low-fat (LF) or low-carbohydrate/Mediterranean (LC/MED) diet [13]. After 6months, participants were re-randomised; half of each study-arm were exposed to moderatelyintense physical-activity ( $\mathrm{PA}^{+} 80 \%$-aerobic; free gym membership) while the other half retained a relatively sedentary lifestyle. Whole-body magnetic-resonance-imaging (3-Tesla-MRI) was performed at $0,6,18$ months. Of the 278 randomized participants $86.3 \%$ completed the trial. While the caloric deficit was similar, the LF group preferentially decreased saturated/unsaturated fats $(p<0.001)$, and the LC/MED decreased carbohydrates $(p<0.001)$ and trans-fat intake 
$\left(\mathrm{p}=0.029\right.$ vs. other diet). The $\mathrm{PA}^{+}$group increased their MET/wk ( $\mathrm{p}=0.009$ vs. $\left.\mathrm{PA}^{-}\right)$. Fat depots/deposits were significantly and variably reduced [Hepatic:(-32\%); deep-subcutaneousadipose-tissue (SAT):(-29\%); visceral-adipose-tissue (VAT):(-25\%); superficial-SAT:(-19\%) and intra-pericardial:(-14\%(-25mL))], with lesser changes of renal:(-9\%); intermuscular:(-2\%) and pancreatic-fat: (-1\%). Although weight loss was comparable, $\mathrm{LC} / \mathrm{MED}^{\mathrm{PA}+}$ favorably reduced waist-circumference and induced $-14 \%$ further loss of intra-pericardial; $p=0.003,-4 \%$ VAT; $p=0.037$ and $-1.9 \%$ pancreatic-fat; $p=0.007$, compared to $\mathrm{LF}^{\mathrm{PA}-}$ changes. $\mathrm{LC} / \mathrm{MED}$ decreased hepatic fat beyond LF diet by $-15 \%$. Conversely, renal-sinus and femoralintermuscular fat dynamics were similarly altered by lifestyle strategies. VAT-loss associated with improved lipids, and deep-SAT loss with improved glycaemia. In conclusion, human depots/ectopic-fat-deposits are substantially variable in their response to different long-term moderate weight-loss strategies. A LC/MED diet, particularly with PA, can favorably enhance fat mobilization in several depots $[14,15]$. Results may suggest protocols for targeting specific fat storage sites.

The discussion centered around how well intervention studies are designed to address these questions, and whether trial participants are generally well stratified so as to generate reliable trial data.

\section{Early signs biomarkers - I}

Diabetic Retinopathy (Tunde Peto)

Diabetic eye disease (DED) is one of the leading causes of blindness in working age adults in the developed world and includes diabetic retinopathy (DR), diabetic maculopathy (DMac) and other 
complications such as cataract and diabetic corneal neuropathy [16]. With the rising DM prevalence DED is also rising. DR/DMac lend themselves to early diagnosis via photographic screening, as the retina's microcirculation is the only visible vascular network in the body and investigations can detect small vascular changes such as microaneurysms, a hallmark of DED $[17,18]$. Good glycaemic, blood pressure and cholesterol control and non-smoking reduces the risk of and delays any visual loss. It is not well-understood if and how vision loss could be further postponed by zinc-related therapies, but using the eye as a marker for early diabetic complications can become a non-invasive signal for vascular complications. As eye-imaging can be repeated frequently it may also be used to facilitate monitoring of other interventions. Even a small delay in DED could give individuals extra years with vision to care for themselves, their family and be in the workforce. People with DED sight-loss have more co-morbidities and longer hospital-stays than those without sight-loss. Preserving sight is increasingly important as many young people have DM and people, including in developing countries now live longer. Good diabetes control has great economic and non-monetary value, keeping people with diabetes in the workforce and after retirement helping with grandchildren and volunteering for different social services. Mobile-phone based imaging and handheld cameras coupled with (semi)-automated image analysis increases retinal imaging availability This may facilitate use of the eye as a surrogate marker for clinical trials and/or nutritional interventions in populations where this had not been possible before.

A very active discussion followed about functional and biochemical changes in the eye in studies of zinc nutrition and the use of eye imaging in both animal models and human studies. Dr Peto confirmed that most clinical imaging and functional tests can be carried out in animals using the 
same or similar imaging devices as in human. Collaborations have already been established for using the eye as a surrogate in animal studies (with Dr Sarah Zangen) and in human supplementation trials (with Dr Nicola Lowe).

\section{Early signs biomarkers - II}

Foot ulcers in diabetes and novel therapies (Mogher Khamaisi)

Chronic foot ulcers often lead to amputations. Peripheral vascular disease, neuropathy, insulin resistance, malnutrition, and reduced resistance to infection related to poor glycaemic control promote poor wound healing [19]. Wound healing requires angiogenesis, cell adhesion, migration, proliferation, differentiation, and extracellular matrix (ECM) deposition, which are often abnormal in DM [20]. Formation of a stable vasculature in response to injury, is essential for restoring blood flow and tissue repair. The mechanisms of and therapeutic targets for wound healing in DM merits further study. Hyperglycaemia, insulin resistance, obesity, other vascular complications and local increase risk of foot ulcers. The efficacy of several treatments, including cytokine replacement and transplantation of keratinocytes or fibroblasts are reduced in DM vs. non-diabetic subjects. Aggressive antibiotic therapy, debridement and negative pressure wound therapy can improve wound healing in DM patients [21].

Fibroblasts are a primary cell for regenerative therapy, due to their secretion of cytokines and angiogenic and immunomodulatory factors. We compared fibroblasts from healthy subjects and from patients with T1DM for 50 years. T1DM fibroblasts demonstrated reduced migratory responses to insulin, decreased vascular endothelial growth factor (VEGF) expression, and less phosphorylated AKT activation. Activated AKT is a downstream effector in the insulin pathway essential for wound healing [22]. Activation of the insulin receptor via 
overexpression of insulin receptor substrate 1 (IRS1) in endothelial cells improved angioblast differentiation, angiogenesis, and epithelialization, and wound healing [23]. However, fibroblast therapy is less effective in DM vs. non-diabetic patients. This may be due to metabolic memory or an ability of the diabetic milieu to rapidly induce cellular abnormalities in normal fibroblasts.

Postnatal somatic cells can be converted into pluripotent-induced stem cells (iPSCs) that can be induced to differentiate into cardiac muscle, vascular smooth muscle, pericytes, hematopoietic stem cells and endothelial cells. Therapeutic iPSCs would involve isolation of differentiated cells from a patient, reprogramming to a pluripotent state, followed by differentiation to the desired cell types for re-implantation. As autologous tissue, this strategy avoids issues of immunogenicity and use of embryonic stem cells (ESs). iPSC transplants may benefit DM wound healing as iPSCs may not retain abnormalities common in fibroblasts from the diabetic host. Future studies will evaluate the efficacy of iPSCs and fibroblasts within the same subjects in enhancing diabetic wound healing, and compare activity of wound healing in iPSCs derived from those without DM.

The discussion that followed concentrated on the similarities and differences in how organs are affected by micro- and macrovascular complications and how different fields might use data from other organ-specific groups. 


\section{Clinical epidemiology - I}

Diabetes complications, pre-eclampsia associated with lower zinc levels, and outreach collaborative opportunities (Alicia Jenkins)

Diabetes mellitus affects $\approx 7.5 \%$ of people in Westernized countries and up to $35 \%$ in high risk regions where poor nutrition is common. Diabetes related complications include fluid and electrolyte imbalance, vascular damage and pregnancy-related complications such as increased rates of pre-eclampsia [24]. Risk factors for complications include hyperglycemia, dyslipidaemia, obesity, hypertension and smoking. Poor diet, including micronutrient disturbances, is implicated in both the onset of DM and its complications [25]. There are few good micronutrient studies in DM, with challenges including the quantification of micronutrient status, including of zinc. Zinc deficiency is implicated in poor maternal and fetal outcomes in pregnancy in the general population, including pre-eclampsia. Some studies have demonstrated that zinc (and other micronutrient supplementation) of the pregnant woman can reduce rates of pre-eclampsia and of child mortality [26].

Pre-eclampsia rates are increased in women with pre-existent T1DM (20\% vs 5\% in non-diabetic women). In our prospective study in 151 women with T1DM in affluent countries higher circulating zinc levels and lower copper/zinc ratios in the first trimester predicted ( $3^{\text {rd }}$ trimester) pre-eclampsia. Confirmatory studies, including in disadvantaged regions and robust measures of circulating and tissue zinc status and supplementation are merited. Resources, including our international collaborative biobank biomarker facility, and the opportunity to collaborate with clinics in disadvantaged regions via two diabetes aid organizations were presented. 
During discussions, major micronutrient (including zinc) related questions in DM were identified and discussed. These related to: (i) relationships with DM onset and complications; (ii) the impact of region / diet / genotypes of study subjects on zinc status; (iii) how to best measure zinc status; (iv) how to increase zinc levels; and (v) clinical impact in epidemiological settings. It was raised that dialogue and international collaborations are needed to take advantage of the collected biomaterial resources and delivery of novel ideas and technologies, especially to disadvantaged countries.

\section{Clinical epidemiology - II}

The Metabolic, Lifestyle and Nutrition Assessment in Young Adult (MELANY) cohort relationships between adolescent weight and adult weight and cardiovascular disease. (Amir

\section{Tirosh)}

Increased body weight in adolescents is associated with increased cardiovascular disease in midlife, but it is yet unclear whether such an association is independently related to higher body weight early in life or to overweight and obesity in adulthood. Moreover, the applicability of the current definition of overweight and obesity in children and adolescents for prediction of future cardiovascular outcomes is controversial. In the session, Dr Tirosh presented his experience studying the Metabolic, Lifestyle and Nutrition Assessment in Young Adult (MELANY) cohort in addressing these questions. The MELANY cohort is a prospective study of $>60,000$ adolescents with repeated anthropometric, biochemical, social and nutritional assessments into midlife $[27,28]$. The study followed 37,674 healthy young teens with BMI of $15-36 \mathrm{~kg} / \mathrm{m}^{2}$ at 
baseline for incident of angiography-proven coronary heart disease (CAD) or type 2 diabetes (T2DM) [29]. During a mean follow-up, 17.4 years, 327 cases of CAD and 1173 cases of T2DM were documented.

In multivariate models adjusted for age, family history, blood pressure, lifestyle factors, and blood biomarkers, elevated adolescent BMI was a significant predictor of angiography-proven CAD (HR, 5.43; 95\%CI;2.77-10.62, for the highest vs. the lowest decile). Further adjustment for BMI at adulthood did not attenuate the association with coronary heart disease (HR, 6.85; 95\% CI;3.30-14.21), as opposed to the complete reversibility of the risk for T2DM observed in this population. BMI values as low as $20.91 \mathrm{~kg} / \mathrm{m}^{2}$ and above were strongly and independently associated with increased incidence of CAD in early adulthood. Incorporating additional biomarkers, such as white blood count further improved prediction. Additional studies of over 2 million male and female adolescents in Israel since 1950s with all-cause mortality records revealed that BMI at age 17 years at the $75^{\text {th }}$ percentile and above $\left(\sim 23.5 \mathrm{~kg} / \mathrm{m}^{2}\right)$ is independently associated with a significant increase in mortality rates during 35 years of follow-up [30].

During discussion, many questions were raised about how well we target patient groups. It became clear that further and better designed studies will need to be conducted at different countries.

\section{Microbiome and diabetes - I}

Links between the gut microbiome, diabetes and zinc (Simon Andrews) 
The gut 'microbiota' represent a diverse, mutualistic community composed mainly of bacteria ( $~ 100$ trillion bacterial cells) that amount to $\sim 2 \%$ of body weight. The microbiota perform a number of important functions that provide significant health benefits including: fermentation of carbohydrates into short-chain fatty acids that provide energy sources for colonic epithelium, liver and muscle tissue; the synthesis of vitamins; metabolism of bile salts and xenobiotics; stimulation of hormone production directing the storage of fat; regulation of gut development; training the immune system; and excluding harmful, pathogenic bacteria. An increasing number of illnesses are being associated with alterations in composition and activity of the gut microbiota, including obesity and T2DM. An increased Firmicute:Bacteroidetes ratio has been linked to obesity and alterations in microbiota composition have likewise been reported for T2DM. Certain probiotics can limit diabetes onset in animals by anti-inflammatory actions, suggesting a role for the microbiota in T2DM. Zinc is essential for microorganisms in the human gut. That germ-free rats require half the level of dietary zinc than fully-colonized controls, indicates that a high proportion of dietary zinc is utilized by the microbiota [31]. Zinc availability is restricted within tissue fluids to deprive invading pathogens - a 'nutritional immunity' strategy. Gut microbiota compete for zinc and change in response to changes in dietary zinc levels [32]. Low zinc availability in the gut enhances virulence for certain bacterial intestinal pathogens [33]. Thus, dietary zinc availability can alter the gut microbiota, which may influence T2DM development.

The group discussed that it is currently uncertain whether dietary zinc affects the microbiota in a way that might influence T2DM onset, and this aspect merits investigation at one of the first sites of action of oral zinc. 


\section{Microbiome and diabetes - II}

The gut microbiome, personalized diets and glycaemia (Niv Zmora)

As an example of how the microbiota may influence onset of T2DM in an individualized manner, a recent study of Zeevi et al. was highlighted [34]. The study goal was to discover new approaches for controlling postprandial blood glucose levels. The Elianv and Segal laboratories monitored postprandial blood glucose levels in 800 healthy and pre-diabetic individuals. Blood parameters, anthropometrics, physical activity, and self-reported lifestyle behaviors, as well as gut microbiota were also recorded. A high degree of interpersonal variability in postprandial glucose response to the same foods was demonstrated. A machine-learning algorithm was then used to integrate these multi-dimensional data to provide an accurate prediction of personalized postprandial glucose responses, which were validated experimentally using further data from a 100-person cohort. Personalized dietary interventions significantly improved postprandial glucose responses accompanied by consistent alterations to the gut microbiota. It was therefore concluded that personalized diets, created with the help of an accurate predictor of blood glucose response that integrates parameters such as dietary habits, physical activity, and gut microbiota, may successfully lower postprandial blood glucose levels and its long-term metabolic consequences. An influence of the gut microbiota in the responses of blood glucose levels to the individually-tailored diets is clearly suggested by the changes in microbiota composition observed, although the mechanisms remain unclear. 
The participants discussed how well these prediction models can be applied to other demographic locations, and how much differing nutritional intake may affect the modelling [35]. However, all agreed, that truly personalized intervention could be on the horizon for all [36].

\section{Related diseases-1}

Mitochondria and obesity links (Atan Gross)

Rates of obesity are increasing globally, which increases rates of pre-diabetes and Type 2 diabetes. Energy expenditure can be considered at whole body level (food intake versus physical activity) and at cellular level. Mitochondria are key regulators of cell energy, and recent advances demonstrate links between the mitochondria, and diabetes and obesity, as well as earlier advances linking the mitochondria to neuromuscular disorders.

Mitochondrial carrier homolog $2(\mathrm{MTCH} 2)$ is a novel regulator of mitochondrial oxidative phosphorylation (OXPHOS) and its locus is associated with increased BMI in humans [37]. Our recent findings demonstrate that mice deficient for muscle $\mathrm{MTCH} 2$ are protected from dietinduced obesity and hyperinsulinaemia, and have increased energy expenditure [38]. Deletion of muscle MTCH2 also increases mitochondrial OXPHOS and mass, triggers conversion from glycolytic to oxidative fibers, increases capacity for endurance exercise, and increases heart function. Moreover, metabolic profiling of mice deficient for muscle $\mathrm{MTCH} 2$ reveals preference to carbohydrate utilization, and an increase in mitochondria and glycolytic flux in muscles, resembling a "starved" phenotype. Thus, how does loss of $\mathrm{MTCH} 2$ protect mice from obesity? Our model is that an increase in mitochondrial respiration and diameter leads to more efficient 
burning of excess nutrients. Ongoing research in this field may lead to the development of mitochondrial targeted therapeutics that may prevent or treat obesity and type 2 diabetes [39].

Lively discussion followed, mostly related to the exact function of mitochondria and whether the model described can indeed explain the findings. It was also highlighted that zinc plays an important role in mitochondrial functions and therefore the connection between diabetes, mitochondria and zinc represent a new research frontier [40].

\section{Related diseases - II}

Zinc in health and disease: a laboratory perspective (Imre Lengyel)

Zinc is essential for normal cellular function; therefore, it is ironic that we know so little about zinc biology. During ageing, changes in zinc homeostasis increase the incidence of age-related degenerative diseases [41]. The aging population are taking zinc supplements in the hope of forestalling maladies associated with ageing. However, without understanding the effects of supplements, their use is questionable. Imre Lengyel described experimental results generated on cells and model animals to understand how zinc supplementation might affect the body at a molecular level. He described efforts to visualize and quantitate how zinc levels are regulated by combining cell and molecular biology with the use of novel fluorescent zinc biosensors and ultrasensitive mass spectrometry. While the Lengyel lab studies the eye, the organ with the highest concentration of zinc in the body, results are likely applicable to other organs. In addition, ocular cells can be readily isolated, cultured and studied, but it is similarly easy to study them in living animals or humans, without surgical intervention, providing an unparalleled 
opportunity to understand and monitor zinc homeostasis and its association with diseases like age-related macular degeneration Alzheimer's disease and diabetes.

There were active discussions on the use of combined measurements of total and exchangeable zinc levels in experiments, which might be a better indicator of zinc status than either total or free zinc alone. There was discussion about issues in collecting biomaterial at remote locations without access to laboratory equipment and refrigeration. It was discussed whether tear could be used for assessing short-term zinc status [42] while nail clipping could provide information for long-term zinc status [43]. The potential to image zinc levels in vivo in the eye in real-time using novel fluorescent biosensors appealed to many, though caution is needed as these sensors interfere with biology, and as such might give misleading results [44]. Nevertheless, the consensus was that the new methodologies will be useful in diagnosis and treatment of diseases in which the role for zinc has been proven and the eye could be appropriate as a "window to the body".

\section{Diabetes and Zinc transporters and enzymes - I}

Zinc transporters and their role in diabetes (Wolfgang Maret)

This section explored the role of 24 human zinc transporter proteins in determining the correct amount of zinc in cells. The zinc transporters belong to two family of proteins: Zip proteins (14 members in humans) and ZnT proteins (10 members in humans). In addition, at least a dozen of metallothioneins participate in the control of cellular zinc homeostasis. Multiple polymorphisms in these proteins are associated with individual differences in zinc metabolism. Zinc has 
insulinomimetic (insulin-sparing) effects on cells targeted by insulin, e.g. muscle, fat tissue. One way of how this effect is expressed is the zinc inhibition of protein tyrosine phosphatases, in particular protein tyrosine phosphatase 1B (PTP1B), which controls signal transduction of the insulin and leptin receptors [45]. Proper control of zinc in pancreatic islets affects insulin and glucagon functions. The zinc transporter ZnT8 is responsible for supplying the dense-core granules (insulin secretory vesicles) of pancreatic $\beta$-cells with zinc. It is of particular interest for diabetes research due to the association of one of its prevalent polymorphic forms with the DM development and the interactions of zinc with insulin and the satiety hormone amylin. Together with calcium, zinc is needed for the storage of crystalline hexameric insulin in the dense-core granules. Furthermore, zinc controls the aggregation state of both insulin and amylin, implicating zinc in the amyloidogenesis of these hormones. Zinc it has paracrine, autocrine, and endocrine effects when co-secreted with insulin and amylin from the pancreatig $\beta$-cells.

The observation in animal models of type 1 or type 2 diabetes that zinc enhances the insulin response, while not enough zinc (zinc deficiency) generates insulin resistance [46, 47], was wellreceived and may lead to collaborations to translate this preventive and therapeutic potential of zinc into clinical practice [48].

\section{Diabetes and Zinc transporters and enzymes - II}

Alpha-1 antitrypsin therapy, inflammation and diabetes (Eli C. Lewis)

Human alpha1-antitrypsin (AAT) is an endogenous circulating anti-inflammatory glycoprotein presently infused weekly and life-long to patients with genetic AAT deficiency, with excellent safety and efficacy. Its anti-inflammatory and immune-modulatory properties make it a potential 
therapeutic agent for other conditions, and its physiology suggests some impact exists in yet understudied areas. Circulating levels of AAT rise during inflammatory flares, as well as during the $3^{\text {rd }}$ trimester of pregnancy and with advanced age. Yet in some conditions, AAT might fail to rise, or fail to function. In a study that addressed failure of AAT to rise during the $3^{\text {rd }}$ trimester of pregnancy, an association was observed to suggest predisposition for premature rupture of membranes, severe preeclampsia, spontaneous abortions and gestational diabetes [49]. In acute graft-versus-host disease (GVHD), gut involvement renders the condition a frank protein-losing enteropathy; indeed, circulating AAT levels drop and stool content is high in AAT. Several clinical trials have addressed this phenomenon by introducing infused AAT to patients with treatment-refractory GVHD and were found to be, quite literally, lifesaving [50]. The challenge of the matter is not the exploration of further applications for AAT infusions, but rather the deciphering of its mode of action. To this end, it is believed that AAT addresses the injured cell, and only then indirectly alters the course of inflammation and immune system trajectories.

The talk focused on research regarding AAT as more than an anti-protease, with many novel binding partners. Endogenous and exogenous AAT are at the junction between the immune system, inflammation, and the injured cell, as reflected by recent clinical trials that span conditions as diverse as T1DM, myocardial infarction, lung transplantation, graft-versus-host disease and cystic fibrosis, and by identifying multiple related co-morbidities in an expansive European four-million-patient study on conditions associated with sub-satisfactory levels of circulating AAT [51].

The phenomenon of immune cell repopulation and its recently appreciated plasticity in the face of local injured tissue, forms a bridge between these pathologies and opens opportunities for 
tissue preconditioning using AAT, particularly when considering cell/organ grafting and wound healing.

The discussion was centered around the notion that while no obvious direct evidence connects AAT and zinc biology, the outcomes of changes in the homeostasis of both agents suggest some functional overlap, perhaps indirectly. Therefore, more integrative studies are warranted.

\section{Concluding remarks}

A diverse multi-disciplinary group of clinicians and basic scientists held a dynamic workshop related to diabetes, obesity and zinc metabolism. Knowledge was shared and wide-ranging discussions were held in a pleasant environment, with interventions (healthy meals and hikes) to reduce the risk of diabetes and obesity in attendees. Ongoing dialogue, collaborations and a follow-up meeting are anticipated.

\section{Acknowledgements}

The organizers and attendees gratefully acknowledge the sponsorship and support of the Friends of Israel Educational Foundation (www.foi-asg.org/asg-workshops-study-tours.php) and the support of Zinc-Net (Zinc-net.org), The Faculty of Health Sciences and the office of the Research and Development at Ben-Gurion University of the Negev. 


\section{References}

[1] G.A. Rutter, P. Chabosseau, E.A. Bellomo, W. Maret, R.K. Mitchell, D.J. Hodson, A. Solomou, M. Hu, Intracellular zinc in insulin secretion and action: a determinant of diabetes risk?, Proc Nutr Soc 75(1) (2016) 61-72.

[2] R. Sladek, G. Rocheleau, J. Rung, C. Dina, L. Shen, D. Serre, P. Boutin, D. Vincent, A. Belisle, S. Hadjadj, B. Balkau, B. Heude, G. Charpentier, T.J. Hudson, A. Montpetit, A.V. Pshezhetsky, M. Prentki, B.I. Posner, D.J. Balding, D. Meyre, C. Polychronakos, P. Froguel, A genome-wide association study identifies novel risk loci for type 2 diabetes, Nature 445(7130) (2007) 881-5.

[3] T.J. Nicolson, E.A. Bellomo, N. Wijesekara, M.K. Loder, J.M. Baldwin, A.V. Gyulkhandanyan, V. Koshkin, A.I. Tarasov, R. Carzaniga, K. Kronenberger, T.K. Taneja, G. da Silva Xavier, S. Libert, P. Froguel, R. Scharfmann, V. Stetsyuk, P. Ravassard, H. Parker, F.M. Gribble, F. Reimann, R. Sladek, S.J. Hughes, P.R. Johnson, M. Masseboeuf, R. Burcelin, S.A. Baldwin, M. Liu, R. Lara-Lemus, P. Arvan, F.C. Schuit, M.B. Wheeler, F. Chimienti, G.A. Rutter, Insulin storage and glucose homeostasis in mice null for the granule zinc transporter ZnT8 and studies of the type 2 diabetes-associated variants, Diabetes 58(9) (2009) 2070-83.

[4] C. Merriman, Q. Huang, G.A. Rutter, D. Fu, Lipid-tuned Zinc Transport Activity of Human ZnT8 Protein Correlates with Risk for Type-2 Diabetes, J Biol Chem 291(53) (2016) 2695026957.

[5] M. Tamaki, Y. Fujitani, A. Hara, T. Uchida, Y. Tamura, K. Takeno, M. Kawaguchi, T. Watanabe, T. Ogihara, A. Fukunaka, T. Shimizu, T. Mita, A. Kanazawa, M.O. Imaizumi, T. Abe, H. Kiyonari, S. Hojyo, T. Fukada, T. Kawauchi, S. Nagamatsu, T. Hirano, R. Kawamori, H. Watada, The diabetes-susceptible gene SLC30A8/ZnT8 regulates hepatic insulin clearance, J Clin Invest 123(10) (2013) 4513-24.

[6] G.A. Rutter, F. Chimienti, SLC30A8 mutations in type 2 diabetes, Diabetologia 58(1) (2015) 31-6.

[7] A. Solomou, E. Philippe, P. Chabosseau, S. Migrenne-Li, J. Gaitan, J. Lang, C. Magnan, G.A. Rutter, Over-expression of SIc30a8/ZnT8 selectively in the mouse alpha cell impairs glucagon release and responses to hypoglycemia, Nutr Metab (Lond) 13 (2016) 46.

[8] J. Flannick, G. Thorleifsson, N.L. Beer, S.B. Jacobs, N. Grarup, N.P. Burtt, A. Mahajan, C. Fuchsberger, G. Atzmon, R. Benediktsson, J. Blangero, D.W. Bowden, I. Brandslund, J.

Brosnan, F. Burslem, J. Chambers, Y.S. Cho, C. Christensen, D.A. Douglas, R. Duggirala, Z. Dymek, Y. Farjoun, T. Fennell, P. Fontanillas, T. Forsen, S. Gabriel, B. Glaser, D.F. Gudbjartsson, C. Hanis, T. Hansen, A.B. Hreidarsson, K. Hveem, E. Ingelsson, B. Isomaa, S. Johansson, T. Jorgensen, M.E. Jorgensen, S. Kathiresan, A. Kong, J. Kooner, J. Kravic, M. Laakso, J.Y. Lee, L. Lind, C.M. Lindgren, A. Linneberg, G. Masson, T. Meitinger, K.L. Mohlke, A. Molven, A.P. Morris, S. Potluri, R. Rauramaa, R. Ribel-Madsen, A.M. Richard, T. Rolph, V. Salomaa, A.V. Segre, H. Skarstrand, V. Steinthorsdottir, H.M. Stringham, P. Sulem, E.S. Tai, Y.Y. Teo, T. Teslovich, U. Thorsteinsdottir, J.K. Trimmer, T. Tuomi, J. Tuomilehto, F. VaziriSani, B.F. Voight, J.G. Wilson, M. Boehnke, M.I. McCarthy, P.R. Njolstad, O. Pedersen, L. Groop, D.R. Cox, K. Stefansson, D. Altshuler, Loss-of-function mutations in SLC30A8 protect against type 2 diabetes, Nat Genet 46(4) (2014) 357-63.

[9] R.E. Black, C.G. Victora, S.P. Walker, Z.A. Bhutta, P. Christian, M. de Onis, M. Ezzati, S. Grantham-McGregor, J. Katz, R. Martorell, R. Uauy, Maternal and child undernutrition and overweight in low-income and middle-income countries, Lancet 382(9890) (2013) 427-451. [10] A. Chu, M. Foster, S. Samman, Zinc Status and Risk of Cardiovascular Diseases and Type 2 Diabetes Mellitus-A Systematic Review of Prospective Cohort Studies, Nutrients 8(11) (2016). [11] J. Capdor, M. Foster, P. Petocz, S. Samman, Zinc and glycemic control: a meta-analysis of randomised placebo controlled supplementation trials in humans, J Trace Elem Med Biol 27(2) (2013) 137-42. 
[12] Izincg.

[13] I. Shai, D. Schwarzfuchs, Y. Henkin, D.R. Shahar, S. Witkow, I. Greenberg, R. Golan, D. Fraser, A. Bolotin, H. Vardi, O. Tangi-Rozental, R. Zuk-Ramot, B. Sarusi, D. Brickner, Z. Schwartz, E. Sheiner, R. Marko, E. Katorza, J. Thiery, G.M. Fiedler, M. Bluher, M. Stumvoll, M.J. Stampfer, Weight loss with a low-carbohydrate, Mediterranean, or low-fat diet, N Engl J Med 359(3) (2008) 229-41.

[14] Y. Gepner, I. Shelef, D. Schwarzfuchs, H. Zelicha, L. Tene, A. Yaskolka Meir, G. Tsaban, N. Cohen, N. Bril, M. Rein, D. Serfaty, S. Kenigsbuch, O. Komy, A. Wolak, Y. Chassidim, R. Golan, H. Avni-Hassid, A. Bilitzky, B. Sarusi, E. Goshen, E. Shemesh, Y. Henkin, M. Stumvoll, M. Bluher, J. Thiery, U. Ceglarek, A. Rudich, M.J. Stampfer, I. Shai, Effect of Distinct Lifestyle Interventions on Mobilization of Fat Storage Pools: The CENTRAL MRI Randomized Controlled Trial, Circulation (2017).

[15] G. Tsaban, A. Wolak, H. Avni-Hassid, Y. Gepner, I. Shelef, Y. Henkin, D. Schwarzfuchs, N. Cohen, N. Bril, M. Rein, D. Serfaty, S. Kenigsbuch, L. Tene, H. Zelicha, A. Yaskolka-Meir, O. Komy, A. Bilitzky, Y. Chassidim, U. Ceglarek, M. Stumvoll, M. Bluher, J. Thiery, D. Dicker, A. Rudich, M.J. Stampfer, I. Shai, Dynamics of intrapericardial and extrapericardial fat tissues during long-term, dietary-induced, moderate weight loss, Am J Clin Nutr 106(4) (2017) 984-995. [16] S.R. Flaxman, R.R.A. Bourne, S. Resnikoff, P. Ackland, T. Braithwaite, M.V. Cicinelli, A. Das, J.B. Jonas, J. Keeffe, J.H. Kempen, J. Leasher, H. Limburg, K. Naidoo, K. Pesudovs, A. Silvester, G.A. Stevens, N. Tahhan, T.Y. Wong, H.R. Taylor, Global causes of blindness and distance vision impairment 1990-2020: a systematic review and meta-analysis, Lancet Glob Health 5(12) (2017) e1221-e1234.

[17] J.G. Lawrenson, E. Graham-Rowe, F. Lorencatto, J. Burr, C. Bunce, J.J. Francis, P. Aluko, S. Rice, L. Vale, T. Peto, J. Presseau, N. Ivers, J.M. Grimshaw, Interventions to increase attendance for diabetic retinopathy screening, Cochrane Database Syst Rev 1 (2018) CD012054.

[18] D.S. Ting, G.C. Cheung, T.Y. Wong, Diabetic retinopathy: global prevalence, major risk factors, screening practices and public health challenges: a review, Clin Exp Ophthalmol 44(4) (2016) 260-77.

[19] H. Brem, M. Tomic-Canic, Cellular and molecular basis of wound healing in diabetes, J Clin Invest 117(5) (2007) 1219-22.

[20] L. Michalik, W. Wahli, Involvement of PPAR nuclear receptors in tissue injury and wound repair, J Clin Invest 116(3) (2006) 598-606.

[21] N. Greer, N.A. Foman, R. MacDonald, J. Dorrian, P. Fitzgerald, I. Rutks, T.J. Wilt, Advanced wound care therapies for nonhealing diabetic, venous, and arterial ulcers: a systematic review, Ann Intern Med 159(8) (2013) 532-42.

[22] M. Khamaisi, S. Katagiri, H. Keenan, K. Park, Y. Maeda, Q. Li, W. Qi, T. Thomou, D. Eschuk, A. Tellechea, A. Veves, C. Huang, D.P. Orgill, A. Wagers, G.L. King, PKCdelta inhibition normalizes the wound-healing capacity of diabetic human fibroblasts, J Clin Invest 126(3) (2016) 837-53.

[23] S. Katagiri, K. Park, Y. Maeda, T.N. Rao, M. Khamaisi, Q. Li, H. Yokomizo, A. Mima, L. Lancerotto, A. Wagers, D.P. Orgill, G.L. King, Overexpressing IRS1 in Endothelial Cells Enhances Angioblast Differentiation and Wound Healing in Diabetes and Insulin Resistance, Diabetes 65(9) (2016) 2760-71.

[24] C.B. Kelly, M.B. Hookham, J.Y. Yu, S.M. Lockhart, M. Du, A.J. Jenkins, A. Nankervis, K.F. Hanssen, T. Henriksen, S.K. Garg, S.M. Hammad, J.A. Scardo, C.E. Aston, C.C. Patterson, T.J. Lyons, Circulating adipokines are associated with pre-eclampsia in women with type 1 diabetes, Diabetologia 60(12) (2017) 2514-2524.

[25] M. Azar, A. Basu, A.J. Jenkins, A.J. Nankervis, K.F. Hanssen, H. Scholz, T. Henriksen, S.K. Garg, S.M. Hammad, J.A. Scardo, C.E. Aston, T.J. Lyons, Serum carotenoids and fat-soluble 
vitamins in women with type 1 diabetes and preeclampsia: a longitudinal study, Diabetes Care 34(6) (2011) 1258-64.

[26] A. Basu, J.Y. Yu, A.J. Jenkins, A.J. Nankervis, K.F. Hanssen, T. Henriksen, B. Lorentzen, S.K. Garg, M.K. Menard, S.M. Hammad, J.A. Scardo, C.E. Aston, T.J. Lyons, Trace elements as predictors of preeclampsia in type 1 diabetic pregnancy, Nutr Res 35(5) (2015) 421-30.

[27] A. Tirosh, I. Shai, D. Tekes-Manova, E. Israeli, D. Pereg, T. Shochat, I. Kochba, A. Rudich, Normal fasting plasma glucose levels and type 2 diabetes in young men, $\mathrm{N}$ Engl J Med 353(14) (2005) 1454-62.

[28] A. Tirosh, A. Rudich, T. Shochat, D. Tekes-Manova, E. Israeli, Y. Henkin, I. Kochba, I. Shai, Changes in triglyceride levels and risk for coronary heart disease in young men, Ann Intern Med 147(6) (2007) 377-85

[29] A. Tirosh, I. Shai, A. Afek, G. Dubnov-Raz, N. Ayalon, B. Gordon, E. Derazne, D. Tzur, A. Shamis, S. Vinker, A. Rudich, Adolescent BMI trajectory and risk of diabetes versus coronary disease, N Engl J Med 364(14) (2011) 1315-25.

[30] G. Twig, A. Afek, A. Shamiss, E. Derazne, M. Landau Rabbi, D. Tzur, B. Gordon, A. Tirosh, Adolescence BMI and trends in adulthood mortality: a study of 2.16 million adolescents, J Clin Endocrinol Metab 99(6) (2014) 2095-103.

[31] J.C. Smith, Jr., E.G. McDaniel, L.D. McBean, F.S. Doft, J.A. Halsted, Effect of microorganisms upon zinc metabolism using germfree and conventional rats, J Nutr 102(6) (1972) 711-9.

[32] L.M. Gielda, V.J. DiRita, Zinc competition among the intestinal microbiota, MBio 3(4) (2012) e00171-12.

[33] J.Z. Liu, S. Jellbauer, A.J. Poe, V. Ton, M. Pesciaroli, T.E. Kehl-Fie, N.A. Restrepo, M.P. Hosking, R.A. Edwards, A. Battistoni, P. Pasquali, T.E. Lane, W.J. Chazin, T. Vogl, J. Roth, E.P. Skaar, M. Raffatellu, Zinc sequestration by the neutrophil protein calprotectin enhances Salmonella growth in the inflamed gut, Cell Host Microbe 11(3) (2012) 227-39.

[34] D. Zeevi, T. Korem, N. Zmora, D. Israeli, D. Rothschild, A. Weinberger, O. Ben-Yacov, D. Lador, T. Avnit-Sagi, M. Lotan-Pompan, J. Suez, J.A. Mahdi, E. Matot, G. Malka, N. Kosower, M. Rein, G. Zilberman-Schapira, L. Dohnalova, M. Pevsner-Fischer, R. Bikovsky, Z. Halpern, E. Elinav, E. Segal, Personalized Nutrition by Prediction of Glycemic Responses, Cell 163(5) (2015) 1079-1094.

[35] C. Mullineaux-Sanders, J. Suez, E. Elinav, G. Frankel, Sieving through gut models of colonization resistance, Nat Microbiol 3(2) (2018) 132-140.

[36] P. Kundu, E. Blacher, E. Elinav, S. Pettersson, Our Gut Microbiome: The Evolving Inner Self, Cell 171(7) (2017) 1481-1493.

[37] L. Buzaglo-Azriel, Y. Kuperman, M. Tsoory, Y. Zaltsman, L. Shachnai, S.L. Zaidman, E. Bassat, I. Michailovici, A. Sarver, E. Tzahor, M. Haran, C. Vernochet, A. Gross, Loss of Muscle MTCH2 Increases Whole-Body Energy Utilization and Protects from Diet-Induced Obesity, Cell Rep 14(7) (2016) 1602-1610.

[38] A. Ruggiero, E. Aloni, E. Korkotian, Y. Zaltsman, E. Oni-Biton, Y. Kuperman, M. Tsoory, L. Shachnai, S. Levin-Zaidman, O. Brenner, M. Segal, A. Gross, Loss of forebrain MTCH2 decreases mitochondria motility and calcium handling and impairs hippocampal-dependent cognitive functions, Sci Rep 7 (2017) 44401.

[39] M. Fex, L.M. Nicholas, N. Vishnu, A. Medina, V.V. Sharoyko, D.G. Nicholls, P. Spegel, H. Mulder, The pathogenetic role of beta-cell mitochondria in type 2 diabetes, J Endocrinol 236(3) (2018) R145-R159.

[40] E. Nam, J. Han, J.M. Suh, Y. Yi, M.H. Lim, Link of impaired metal ion homeostasis to mitochondrial dysfunction in neurons, Curr Opin Chem Biol 43 (2017) 8-14.

[41] R. Giacconi, L. Costarelli, F. Piacenza, A. Basso, L. Rink, E. Mariani, T. Fulop, G.

Dedoussis, G. Herbein, M. Provinciali, J. Jajte, I. Lengyel, E. Mocchegiani, M. Malavolta, Main 
biomarkers associated with age-related plasma zinc decrease and copper/zinc ratio in healthy elderly from ZincAge study, Eur J Nutr 56(8) (2017) 2457-2466.

[42] Z. Torok, T. Peto, E. Csosz, E. Tukacs, A.M. Molnar, A. Berta, J. Tozser, A. Hajdu, V. Nagy, B. Domokos, A. Csutak, Combined Methods for Diabetic Retinopathy Screening, Using Retina Photographs and Tear Fluid Proteomics Biomarkers, J Diabetes Res 2015 (2015) 623619.

[43] K. He, Trace elements in nails as biomarkers in clinical research, Eur J Clin Invest 41(1) (2011) 98-102.

[44] W. Maret, Analyzing free zinc(II) ion concentrations in cell biology with fluorescent chelating molecules, Metallomics 7(2) (2015) 202-11.

[45] E. Bellomo, K. Birla Singh, A. Massarotti, C. Hogstrand, W. Maret, The metal face of protein tyrosine phosphatase 1B, Coord Chem Rev 327-328 (2016) 70-83.

[46] J. Quarterman, C.F. Mills, W.R. Humphries, The reduced secretion of, and sensitivity to insulin in zinc-deficient rats, Biochem Biophys Res Commun 25(3) (1966) 354-8.

[47] G. Vardatsikos, N.R. Pandey, A.K. Srivastava, Insulino-mimetic and anti-diabetic effects of zinc, J Inorg Biochem 120 (2013) 8-17.

[48] W. Maret, Zinc in Pancreatic Islet Biology, Insulin Sensitivity, and Diabetes, Prev Nutr Food Sci 22(1) (2017) 1-8.

[49] O. Guttman, B.M. Baranovski, R. Schuster, Z. Kaner, G.S. Freixo-Lima, N. Bahar, N. Kalay, M.I. Mizrahi, I. Brami, D.E. Ochayon, E.C. Lewis, Acute-phase protein alpha1-anti-trypsin:

diverting injurious innate and adaptive immune responses from non-authentic threats, Clin Exp Immunol 179(2) (2015) 161-72.

[50] J.M. Magenau, S.C. Goldstein, D. Peltier, R.J. Soiffer, T. Braun, A. Pawarode, M.M. Riwes, M. Kennel, J.H. Antin, C.S. Cutler, V.T. Ho, E.P. Alyea, B.L. Parkin, G.A. Yanik, S.W. Choi, E.C. Lewis, C.A. Dinarello, J. Koreth, P. Reddy, alpha1-Antitrypsin Infusion for treatment of Steroid Resistant Acute Graft-versus-Host Disease, Blood (2018).

[51] C.L. Sanders, A. Ponte, F. Kueppers, The Effects of Inflammation on Alpha 1 Antitrypsin Levels in a National Screening Cohort, COPD 15(1) (2018) 10-16. 